\title{
Injury during Pregnancy and Nervous System Birth Defects: Texas, 1999 to 2003
}

\author{
Erin K. Sauber-Schatz ${ }^{1,2 *}$ Lisa M. Bodnar, ${ }^{1}$ Harold B. Weiss, ${ }_{1}^{1,3}$ John W. Wilson, ${ }^{4}$ \\ Mark D. Pearlman, ${ }^{5}$ and Nina Markovic ${ }^{1}$ \\ ${ }^{1}$ University of Pittsburgh, Graduate School of Public Health, Department of Epidemiology, Pittsburgh, Pennsylvania \\ ${ }^{2}$ Centers for Disease Control and Prevention, National Center for Injury Research and Control, Division of Unintentional \\ Injury Prevention, Atlanta, Georgia (Currently) \\ ${ }^{3}$ University of Otago, School of Medicine, Department of Preventive and Social Medicine, Injury Prevention Research Unit, \\ Dunedin, New Zealand (Currently) \\ ${ }^{4}$ University of Pittsburgh, Graduate School of Public Health, Department of Biostatistics, Pittsburgh, Pennsylvania \\ ${ }^{5}$ University of Michigan, Department of Surgery and Department of Obstetrics and Gynecology, Ann Arbor, Michigan
}

Received 26 February 2013; Revised 15 March 2013; Accepted 9 April 2013

\begin{abstract}
BACKGROUND: Case reports and series have suggested an association between injury during pregnancy and several nervous system and nervous system-related adverse fetal/neonatal outcomes. This study's purpose is to further determine if there is an association between injury during pregnancy and nervous system birth defects in infancy. METHODS: Through a case-control study, the association between injury during pregnancy and nervous system birth defects was tested using the Texas Birth Defects Registry (1999-2003). Semiautomated probabilistic bias analysis was used to correct for systematic error from misclassification of injury during pregnancy. RESULTS: Of the 59,750 infants eligible for this study, 4144 (6.94\%) were diagnosed with a nervous system birth defect and $315(0.53 \%)$ of the infants' mothers were injured during pregnancy. Among these 315 women, $25(7.94 \%)$ delivered an infant with a subsequent nervous system birth defect. The adjusted odds ratio for the association between injury during pregnancy and nervous system birth defects among all study infants was 1.00; 95\% confidence interval, $0.63-1.56$ and $2.44 ; 95 \%$ confidence interval, 1.08-5.53 among breech presentation infants. Probabilistic bias analysis supported these findings. CONCLUSION: No association between injury during pregnancy and nervous system birth defects was identified. Further exploration into the association among breech presentation infants is warranted. Birth Defects Research (Part A) 97:641-648, 2013. (C) 2013 Wiley Periodicals, Inc.
\end{abstract}

Key words: injury; pregnancy; birth defects; central nervous system; Texas

\section{INTRODUCTION}

Approximately $7 \%$ of pregnant women experience injury during pregnancy (Peckham and King, 1963; Tinker et al., 2010); 3.9\% of all pregnant women sustain an injury during pregnancy that results in a visit to an emergency department (Weiss et al., 2008); and 0.3 to $0.4 \%$ of pregnant women will have a trauma-related hospital admission (Lavin and Polsky, 1983). The causes of injury during pregnancy are thought to parallel the general population's (Weintraub et al., 2006), because pregnant women in the United States usually continue most everyday activities throughout pregnancy (Colburn, 1999). Some of the most frequent causes of injury during pregnancy are motor vehicle crashes, falls, being hit by an object or person, burns, poisoning, being cut or pierced, and overexertion. Motor vehicle crashes are the primary reported cause of serious injury during pregnancy (Connolly et al., 1997; Shah et al., 1998; Baerga-Varela et al., 2000; Weiss et al., 2001; Ikossi et al., 2005; Leroy-Malherbe et al., 2006; Weiss, 2006; Nannini et al., 2008; Kvarnstrand et al., 2008).

Injury during pregnancy has been associated with several adverse fetal and pregnancy outcomes (Pearlman et al., 1990; Wolf et al., 1993; Greenblatt et al., 1997; Klinich et al., 1998; Weiss, 1999; Corona-Rivera et al., 2001; Hyde et al., 2003; El-Kady et al., 2004; Schiff and

No financial support was received for this work. The authors have no conflicts of interest.

*Correspondence to: Erin K. Sauber-Schatz, 4770 Buford Highway, N.E., Mailstop F62, Atlanta, GA 30341 E-mail: esauberschatz@cdc.gov

Published online 25 July 2013 in Wiley Online Library (wileyonlinelibrary. com).

DOI $10.1002 /$ bdra. 23143 
Holt, 2005; Weiss, 2006; Kuo et al., 2007; Klinich et al., 2008; Oxford and Ludmir, 2009). In addition, fetal brain injury (Bowdler et al., 1987; Stafford et al., 1988; Knuppel et al., 1994; Ankuist et al., 1994; Baethmann et al., 1996; Litmanovitz et al., 2000), long bone fractures (Crosby, 1974), intraabdominal injuries (Fries et al., 1989; Parida et al., 1999), and intrathoracic injuries (Sherer et al., 1993; Litmanovitz et al., 2000) have been reported due to motor vehicle crashes during pregnancy. Although there are many associations between injury during pregnancy and adverse pregnancy and fetal outcomes, few studies have examined the relationship between injury during pregnancy and birth defects (Richards, 1969; Tinker et al., 2011).

Approximately 150,000 infants (Petrini et al., 2002), or $3 \%$ of all live born infants, are born with a birth defect in the United States each year (Honein et al., 1999; Centers for Disease Control and Prevention, 2012a). For at least the past 20 years, birth defects have been the leading cause of infant mortality in the United States, accounting for approximately $20 \%$ of all infant deaths (Petrini et al., 2002). However, less than $4 \%$ of infants born with a birth defect will die within the first year of life (Petrini et al., 2002), and of those that do, more than $70 \%$ of the deaths occur in the neonatal period (Anderson, 2001). The infants that survive with a birth defect often face lifelong challenges including a greater chance of death and illness, such as mild health problems, social challenges, long term disability, and reduced quality of life, when compared with infants without birth defects (Petrini et al., 2002; Centers for Disease Control and Prevention 2012b).

Despite the public health implications of birth defects, in 65 to $70 \%$ of birth defect cases, the cause of the birth defect remains unknown (Institute of Medicine, 2003). It has been reported that any alteration in the developmental processes of the fetus may cause severe nervous system birth defects (Rice and Barone, 2000) and injury during pregnancy could be a mechanism for alteration. Furthermore, case reports and case series have suggested an association between injury during pregnancy and several nervous system and nervous system-related fetal/ neonatal (Richards, 1969; Bowdler et al., 1987; Baethmann et al., 1996; Strigini et al., 2001; Hagmann et al., 2004; Leroy-Malherbe et al., 2006) and infant (Bowdler et al., 1987; Litmanovitz et al., 2000) outcomes. However, the association between injury during pregnancy and select nervous system birth defects on a population level has only recently been examined and no association was found (Tinker et al., 2011). The purpose of this study is to further explore the potential association between injury during pregnancy and nervous system birth defects in infancy.

\section{MATERIALS AND METHODS Data Collection}

Birth defects data were obtained from the Texas Birth Defects Registry (TBDR) (Centers for Disease Control and Prevention, 2012c). The TBDR is a population-based registry that uses active surveillance and began collecting birth defects data in 1996 with statewide surveillance beginning in 1999 (Texas Birth Defects Epidemiology and Surveillance Branch, 2012a). Registry data are collected by trained program staff that visit medical facilities to review log books, hospital discharge lists, and other records to create a list of potential birth defect cases. Program staff then review the medical charts of each potential case. If the infant or fetus is determined to have at least one of the birth defects covered by the registry, they are included in the registry and detailed demographic and diagnostic information is abstracted from their records. Quality control procedures are in place for finding cases, abstracting information, and coding defects from the records to help ensure the registry's completeness and accuracy. Records based on abstracted medical information are then matched to vital statistics records including birth certificates and fetal death certificates from the Vital Statistics Unit at the Texas Department of State Health Services. Further details on the TBDR and its inclusion/exclusion criteria have been described elsewhere (Texas Birth Defects Epidemiology and Surveillance Branch, 2012a; Texas Department of State Health Services, 2012).

\section{Study Population}

Inclusion criteria for this study were that the infant was born during 1999-2003, was a live birth, and was not diagnosed with any chromosomal birth defects (British Pediatric Association [BPA] code 758; $\mathrm{N}=5908$ ). Cases classified as a spontaneous fetal death $(\mathrm{N}=1547)$, induced termination of pregnancy $(\mathrm{N}=1745)$, or an unspecified fetal death/pregnancy termination $(\mathrm{N}=100)$ were excluded from this study. The study population consisted of 59,750 live born infants.

\section{Definition of Cases and Controls and Exposure of Interest}

The case definition was diagnosis of a nervous system birth defect as indicated by a BPA code of 742 in the TBDR. The BPA code 742 includes: encephalocele, microcephalus, reduction deformities of the brain, congenital hydrocephalus, other specified anomalies of the brain, other specified anomalies of the spinal cord, other specified anomalies of the nervous system, and unspecified anomalies of the brain, spinal cord, and nervous system. Study controls consisted of all remaining infants in the TBDR, after the exclusions discussed above, that were diagnosed with a birth defect other than a nervous system birth defect. The exposure of interest was maternal injury during pregnancy. An infant was classified as exposed to a maternal injury during pregnancy if injury during pregnancy was indicated as a maternal illness, condition, or complication the infant's TBDR record. Maternal injury during pregnancy was a dichotomous variable, but included abdominal trauma, abuse, motor vehicle crash, gunshot wound, or the general category of "injuries during this pregnancy." No information was available on the timing or severity of injury, and, due to inconsistent measurement of injury mechanism between study years, injury mechanism was not able to be accurately analyzed.

\section{Data Analysis}

Logistic regression was used to test the association between injury during pregnancy and nervous system birth defects. The main effects model was built using univariate analysis followed by step-up and then step- 
Table 1

Frequency and Percentage of Injury during Pregnancy by Nervous System Defects: Texas, 1999 to 2003

\begin{tabular}{|c|c|c|c|c|c|}
\hline \multirow[b]{2}{*}{ Type of nervous system birth defect (BPA code) } & \multicolumn{5}{|c|}{ Injury during pregnancy } \\
\hline & $\mathrm{N}$ & Yes & $\%$ & No & $\%$ \\
\hline No. of infants with any nervous system birth defect (742) & 4,144 & 25 & 0.60 & 4,119 & 99.40 \\
\hline Other specified anomalies of brain (742.4) & 1,513 & 8 & 0.53 & 1,505 & 99.47 \\
\hline Congenital hydrocephalus (742.3) & 1,159 & 4 & 0.35 & 1,155 & 99.65 \\
\hline Microcephalus (742.1) & 1,085 & 9 & 0.83 & 1,076 & 99.17 \\
\hline Reduction deformities of brain (742.2) & 927 & 7 & 0.76 & 920 & 99.24 \\
\hline Other specified anomalies of spinal cord (742.5) & 303 & 3 & 0.99 & 300 & 99.01 \\
\hline Encephalocele (742.0) & 118 & 1 & 0.85 & 117 & 99.15 \\
\hline Other specified anomalies of nervous system (742.8) & 82 & 1 & 1.22 & 81 & 98.78 \\
\hline Unspecified anomalies of brain, spinal cord and nervous system (742.9) & 9 & 0 & 0.00 & 9 & 100.00 \\
\hline
\end{tabular}

BPA, British Pediatric Association.

down regression. First-order interactions among the main effects variables were tested through univariate analysis followed by a global test for interactions and step-down regression (Sauber-Schatz, 2008). The final built model adjusted for infant gender, gestational age at birth, maternal race (white vs. non-white), maternal education (greater or less than high school), low birth weight, tobacco use during pregnancy, number of birth defects, hydramnios, breech presentation, and umbilical cord complications (Hosmer-Lemeshow $p=0.0613$ ). A significant effect modification on the multiplicative scale between breech presentation and injury during pregnancy was identified ( $p$ value $=0.0161)$; therefore, stratified analyses (breech and nonbreech) were performed.

\section{Probabilistic Bias Analysis}

Semiautomated probabilistic bias analysis was used to correct for systematic error due to misclassification of injury during pregnancy (Lash and Fink, 2003; Fox et al., 2005). This analysis results in three intervals and graphs of the distribution. The first interval, the conventional odds ratio and $95 \%$ confidence interval, only accounts for random error (Fox et al., 2005). The second and third simulation intervals account for systematic error only and both the systematic and random error, respectively (Fox et al., 2005). The methods of the analysis are described in more detail elsewhere (Lash and Fink, 2003; Fox et al., 2005). Misclassification of injury during pregnancy was specified as nondifferential (Szklo and Nieto, 2000), sensitivity was set equal to 0.075 to account for extreme exposure misclassification, and 1.0 was used as the specificity because indication of exposure was considered accurate. Based on injury during pregnancy counts within strata, a sensitivity of 0.095 for breech presentation and a sensitivity of 0.073 for nonbreech presentation were used.

All analyses were conducted in SAS 9.1 (SAS Institute, Cary, NC). This study was approved by the University of Pittsburgh's Institutional Review Board.

\section{RESULTS}

Of the 59,750 study infants, 4,144 (6.9\%) were diagnosed with at least one nervous system birth defect (BPA code 742). Injuries during pregnancy were reported among $315(0.53 \%)$ of the 59,750 infants; of these, 25
(7.9\%) were also diagnosed with a nervous system birth defect (Table 1). A higher percentage of women who were injured during pregnancy were younger in age, Black or Hispanic, born in the United States, reported alcohol use during pregnancy, reported tobacco use during pregnancy, had breech presentation at delivery, had hydramnios, and had umbilical cord complications compared with women who were not injured during pregnancy (Table 2).

The unadjusted odds ratio (OR) and adjusted odds ratio (aOR) with corresponding 95\% confidence intervals (95\% CI) for the association between injury during pregnancy and nervous system birth defects were OR, 1.16; 95\% CI, 0.77-1.76 and aOR, 1.00; 95\% CI, 0.63-1.56, respectively (Table 3 ). Accounting for exposure misclassification changed the OR for the unadjusted analysis very little: OR, 1.17; 95\% CI, 0.77-1.80. Whereas, the aOR moved slightly upward and away from the null $\mathrm{aOR}=1.16,95 \% \mathrm{CI}, 0.73-1.85$ when accounting for exposure misclassification (Table 3 ). This suggests that the misclassification of injury during pregnancy in the conventional analysis was biased slightly toward the null, but not enough to effect the overall conclusion of no association.

Breech presentation modified the effect of injury during pregnancy on the risk of a nervous system birth defect. Of the infants with a breech presentation $(n=6001), 40$ were exposed to a maternal injury during pregnancy and 610 were diagnosed with a nervous system birth defect. Among infants diagnosed with a breech presentation, the infants who were exposed to a maternal injury during pregnancy were more likely to be diagnosed with a nervous system birth defect than those who were not exposed to a maternal injury during pregnancy aOR, 2.44; 95\% CI, 1.08-5.53 (Table 4). Among pregnancies with nonbreech presentation, there was no association aOR, 0.73 ; $95 \%$ CI, $0.42-1.30$.

Accounting for exposure misclassification increased the OR for the adjusted analysis among breech presentation infants: aOR, 3.34; 95\% CI, 1.43-7.85 (Table 4). This suggests that the misclassification of injury during pregnancy among breech presentation infants was biased toward the null. For nonbreech presentation, the aOR increased slightly when exposure misclassification was accounted for: aOR, 0.81 ; 95\% CI,0.44-1.46, but there remained no association (Table 4). 
Table 2

Maternal, Pregnancy, and Infant Variables by Injury during Pregnancy Status: Texas, 1999 to 2003

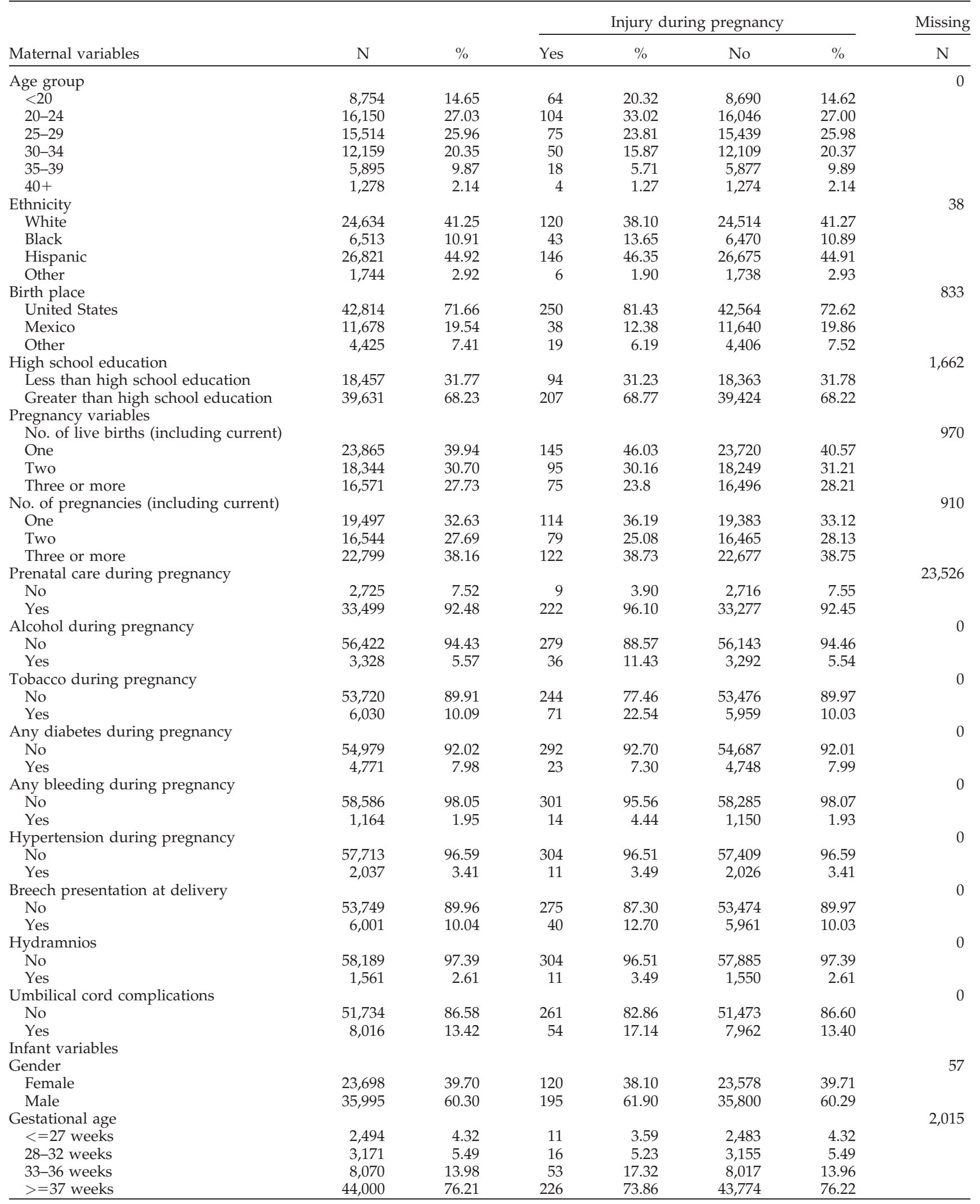


Table 2. (continued).

\begin{tabular}{|c|c|c|c|c|c|c|c|}
\hline \multirow[b]{2}{*}{ Maternal variables } & \multirow[b]{2}{*}{$\mathrm{N}$} & \multirow[b]{2}{*}{$\%$} & \multicolumn{4}{|c|}{ Injury during pregnancy } & \multirow{2}{*}{$\frac{\text { Missing }}{\mathrm{N}}$} \\
\hline & & & Yes & $\%$ & No & $\%$ & \\
\hline Birth weight & & & & & & & 3,640 \\
\hline Low $(<2500$ grams $)$ & 11,920 & 19.95 & 67 & 21.27 & 11,853 & 19.94 & \\
\hline Normal (2500-3999 grams) & 43,210 & 72.32 & 229 & 72.70 & 42,981 & 72.32 & \\
\hline High $(>=4000$ grams $)$ & 4,620 & 7.73 & 19 & 6.03 & 4,601 & 7.74 & \\
\hline No. of birth defects & & & & & & & 0 \\
\hline 1 & 26,962 & 45.12 & 135 & 42.86 & 26,827 & 45.14 & \\
\hline 2 & 12,510 & 20.94 & 60 & 19.05 & 12,450 & 20.95 & \\
\hline 3 & 7,175 & 12.01 & 44 & 13.97 & 7,131 & 12.00 & \\
\hline 4 & 4,270 & 7.15 & 20 & 6.35 & 4,250 & 7.15 & \\
\hline $5+$ & 8,833 & 14.79 & 56 & 17.78 & 8,777 & 14.77 & \\
\hline Infant died during first year of life & & & & & & & 0 \\
\hline No & 57,049 & 95.48 & 16 & 5.08 & 2,685 & 4.52 & \\
\hline Yes & 2,701 & 4.52 & 299 & 94.92 & 56,750 & 95.48 & \\
\hline
\end{tabular}

\section{DISCUSSION}

Although case reports and case series have suggested an association between injury during pregnancy and several nervous system and nervous system-related fetal/ neonatal outcomes (Bowdler et al., 1987; Baethmann et al., 1996; Litmanovitz et al., 2000; Hagmann et al., 2004; Leroy-Malherbe et al., 2006), this study replicated prior findings by Tinker et al. (2011) of no association between injury during pregnancy and nervous system birth defects on the population level. Perhaps the main difference between the case reports and case series and the population-based studies is the lacking detail on injury severity, timing, and mechanism that was a limitation in this study and Tinker et al. (2011). The limited injury information both in quantity and quality might account for the observed null findings.

The TBDR is one of the few databases that includes information on injury during pregnancy and birth defects, but there is no timing of injury, severity of injury, or consistent mechanism of injury information available. Timing of injury information is important to assess when available, because the various regions of the brain form at different times; therefore, the timing of insults, their

Table 3

Probabilistic Bias Analyses Results for the Association between Injury during Pregnancy and Nervous System Birth Defects: Texas, 1999 to 2003

\begin{tabular}{lll}
\hline Analyses $^{\mathrm{a}}$ & OR & $95 \% \mathrm{CI}$ \\
\hline Unadjusted analysis & & \\
$\quad$ Conventional analysis & 1.16 & $(0.77-1.76)$ \\
$\quad$ Sensitivity analysis & 1.17 & $(1.05-1.31)$ \\
$\quad$ Total error analysis & 1.17 & $(0.77-1.80)$ \\
Adjusted analysis & & \\
$\quad$ Conventional analysis & 1.00 & $(0.63-1.56)$ \\
$\quad$ Sensitivity analysis & 1.16 & $(1.03-1.31)$ \\
$\quad$ Total error analysis & 1.16 & $(0.73-1.85)$ \\
\hline
\end{tabular}

${ }^{\mathrm{a}} 10,000$ Iterations, Sensitivity $=0.075$, Specificity $=1.0$.

${ }^{\mathrm{b}}$ Adjustment variables: infant gender, gestational age at birth, maternal race, maternal education, low birth weight, tobacco use during pregnancy, number of birth defects, hydramnios, breech presentation, and umbilical cord complications.

$\mathrm{OR}$, odds ratio; $\mathrm{CI}$, confidence interval. severity, and nature will likely determine the type or pattern of brain injury, how the neurological disorder is expressed, and the extent to which the individual's functioning abilities will be affected (Rees and Harding; 2004). When available, assessing the timing of injury in future studies should be done to help identify windows of vulnerability for adverse nervous system outcomes following injury during pregnancy. It has also been shown that regardless of the severity of a pregnant woman's injury, the pregnancy and/or fetus can still experience adverse outcomes and even fetal death (Agran et al., 1987; Fries et al., 1989; Esposito et al., 1991; Poole et al., 1996; Baerga-Varela et al., 2000; Schiff and Holt,

Table 4

Probabilistic Bias Analyses Results for the Association between Injury during Pregnancy and Nervous System Birth Defects, Stratified by Breech and Nonbreech Presentation: Texas, 1999 to 2003

\begin{tabular}{|c|c|c|}
\hline Parameter & OR & $95 \% \mathrm{CI}$ \\
\hline \multicolumn{3}{|l|}{ Breech analyses $^{\mathrm{a}}$} \\
\hline \multicolumn{3}{|l|}{ Unadjusted analysis } \\
\hline Conventional analysis & 2.99 & $(1.45-6.03)$ \\
\hline Sensitivity analysis & 3.38 & $(2.69-4.23)$ \\
\hline Total error analysis & 3.38 & $(1.59-7.28)$ \\
\hline \multicolumn{3}{|l|}{ Adjusted analysis ${ }^{b}$} \\
\hline Conventional analysis & 2.44 & $(1.08-5.53)$ \\
\hline Sensitivity analysis & 3.35 & $(2.60-4.25)$ \\
\hline Total error analysis & 3.34 & $(1.43-7.85)$ \\
\hline \multicolumn{3}{|l|}{ Nonbreech analyses ${ }^{c}$} \\
\hline \multicolumn{3}{|l|}{ Unadjusted analysis } \\
\hline Conventional analysis & 0.82 & $(0.49-1.40)$ \\
\hline Sensitivity analysis & 0.81 & $(0.71-0.93)$ \\
\hline Total error analysis & 0.82 & $(0.47-1.40)$ \\
\hline \multicolumn{3}{|l|}{ Adjusted analysis ${ }^{b}$} \\
\hline Conventional analysis & 0.73 & $(0.42-1.30)$ \\
\hline Sensitivity analysis & 0.81 & $(0.69-0.93)$ \\
\hline Total error analysis & 0.81 & $(0.44-1.46)$ \\
\hline \multicolumn{3}{|c|}{$\begin{array}{l}{ }^{\mathrm{a}} 10,000 \text { Iterations, Sensitivity }=0.095 \text {, Specificity }=1.0 \text {. } \\
{ }^{\mathrm{b}} \text { Adjustment variables: infant gender, gestational age at birth, } \\
\text { maternal race, maternal education, low birth weight, tobacco use } \\
\text { during pregnancy, number of birth defects, hydramnios, breech } \\
\text { presentation, and umbilical cord complications. } \\
{ }^{c} 10,000 \text { Iterations, Sensitivity }=0.073 \text {, Specificity }=1.0 . \\
\text { OR, odds ratio; CI, confidence interval. }\end{array}$} \\
\hline
\end{tabular}


2002; Schiff et al., 2002; Grossman, 2004; Schiff and Holt, 2005). Therefore, similar to injury timing, when available, injury severity should be analyzed to further explore different types or severities of adverse maternal and fetal outcomes following various severities of injury. Data and future studies should account for timing of injury, injury severity, and injury mechanisms when available. However, for that data to be available for study, injuries need to be assessed, reported, and recorded in detail.

The strong association between injury during pregnancy and nervous system birth defects among infants with breech presentation was a novel finding that should be further explored. Breech presentation can be caused by underlying fetal or maternal abnormality, can be a chance occurrence, or can reportedly be related to a benign variant such as cornual placental position (Cluver et al., 2012). Although the cause of breech may be unknown, it is reported in approximately 3 to $4 \%$ of term pregnancies (Hickok et al., 1992). In this study, $12.7 \%$ of infants whose mother was injured during pregnancy and $10.0 \%$ of infants whose mother was not injured during pregnancy were breech presentation at delivery; this is a much higher percentage than is seen in the general population, but not unexpected. Birth defects are associated with breech presentation (Rayl et al., 1996; Ford et al., 2010), and fetal mobility can be affected by neurologic defects (Sival, 1993). However, it is unknown what is actually driving the association among breech presentation infants in this study. It can be speculated that through direct injury, reproductive organ injury, iatrogenic effects, hypoxia or ischemia, and/ or stress, an injury during pregnancy may disrupt a developmental pathway leading to a nervous system birth defect, which in turn affects the normal rotation of the fetus and results in breech presentation. More research is needed to better understand if this finding is due to preexisting neurologic conditions that led to the breech presentation, or if breech pregnancy increases the likelihood of neurologic injury resulting from trauma.

\section{Strengths and Limitations}

There are several strengths to this study. The first is the choice of the data source. Both cases and controls were identified from the TBDR. Therefore, both groups were subjected to the same active surveillance data collection efforts and recall regarding exposure, so no bias is introduced (Gordis, 2000). However, because controls were infants diagnosed with other birth defects and a few select birth defects have recently been associated with injury during pregnancy (Tinker et al., 2011), it is possible that there is a bias toward the null for the association between injury during pregnancy and nervous system birth defects. A second strength of this study is that, because trauma during pregnancy is relatively rare, it is ideal to study using large secondary data sources (Ikossi et al., 2005), such as the TBDR. Another strength is that many studies that examine the role of trauma during pregnancy focus on hospitalization or fetal death reviews (Hyde et al., 2003), but by using the TBDR, the women who were injured during pregnancy did not need to be hospitalized for their injury or experience the severe outcome of fetal death to be included in this study. This could also be seen as a study limitation, in that the inclusion of minor injuries might dilute or mask associations. A final strength is that we were able to report secondary ORs and 95\% CIs that better quantifies the results when misclassification exists by using the probabilistic bias analysis.

A limitation of this study was the potential for the TBDR to miss cases of birth defects that were eligible for inclusion into the registry. For instance, birth defect cases are not included in the registry if they are diagnosed beyond an infant's first year of life (other than cases of fetal alcohol syndrome). This is an important limitation to consider when studying nervous system birth defects because nervous system birth defects might not be diagnosed until later in life when a child is not meeting developmental milestones. Another way cases could be missed is if they were diagnosed outside of Texas or in prenatal diagnostic facilities or private physicians' offices (which are not included in the TBDR) (Texas Birth Defects Epidemiology and Surveillance Branch, 2012b). A second limitation of this study is that the data are older. The TBDR currently has more recent years of data available, but adding more recent years of data is not feasible. The data management involved in merging and linking the 1999 to 2003 data and combining and collapsing study variables for consistency in definition was highly involved and time consuming. A final study limitation is that the generalizability of the study results beyond the state of Texas is unknown.

\section{Future Research}

This study's significant and novel finding of an association between injury during pregnancy and nervous system birth defects among breech presentation infants merits further exploration. Going beyond this study's scope and overall outcome of nervous system birth defects, there are other birth defects (Tinker et al., 2011), specific nervous system birth defects, and other neurorelated outcomes that should be assessed in future studies. Especially because neurodevelopmental disabilities affect 3 to $8 \%$ of the 4 million babies born each year in the United States (Weiss and Landrigan, 2000) and the cause of fewer than $25 \%$ of neurodevelopmental disabilities such as dyslexia, attention deficit hyperactivity disorder, intellectual retardation, and autism is known (Weiss and Landrigan, 2000). Support for these hypotheses could be garnered from Morris et al. who reported that approximately $40 \%$ of the neonates in their study that survived emergency cesarean section following maternal trauma had moderate to serious disabilities, many had neurobehavioral dysfunction and poor school performance (Morris et al., 1996). Therefore, the association between injury during pregnancy and other neurorelated outcomes should be considered, while also taking into consideration gestational age at birth. In conclusion, although no association between injury during pregnancy and nervous system birth defects was found in this study, the literature continues to support injury during pregnancy as a preventable risk factor for many adverse pregnancy, fetal, and infant outcomes on a case level. The novel association between injury during pregnancy and nervous system birth defects among infants with breech presentation should be further explored.

\section{REFERENCES}

Agran PF, Dunkle DE, Winn DG, Deryck K. 1987. Fetal death in motor vehicle accidents. Ann Emerg Med 16:1355-1358. 
Anderson RN. 2001. Deaths: leading causes for 1999. Natl Vital Stat Rep 49:1-87.

Ankuist KW, Parnes S, Cargill Y, Tawagi G. 1994. An unexpected fetal outcome following a severe maternal motor vehicle accident. Obstet Gynecol 84:656-659.

Baerga-Varela Y, Zietlow SP, Bannon MP, et al. 2000. Trauma in pregnancy. Mayo Clin Proc 75:1243-1248.

Baethmann M, Kahn T, Lenard HG, Voit T. 1996. Fetal CNS damage after exposure to maternal trauma during pregnancy. Acta Paediatr 85:1331-1338

Bowdler N, Faix RG, Elkins T. 1987. Fetal skull fracture and brain injury after a maternal automobile accident. A case report. J Reprod Med 32:375-378

Centers for Disease Control and Prevention. 2012a. Facts about birth defects. Available at: http://www.cdc.gov/NCBDDD/birthdefects / facts.html. Accessed April 29, 2013.

Centers for Disease Control and Prevention. 2012b. Birth defects. Available at: http://www.cdc.gov/ncbddd/birthdefects/index.html. Accessed March 15, 2013.

Centers for Disease Control and Prevention. 2012c. Centers for Birth Defects Research and Prevention: National Birth Defects Prevention Study (NBDPS). Available at: http://www.cdc.gov/ncbddd/bd/ nbdps.htm\#states. Accessed March 15, 2013.

Cluver C, Hofmeyr G, Gyte G, Sinclair M. 2012. Interventions for helping to turn term breech babies to head first presentation when using external cephalic version. Cochrane Database Syst Rev 1:CD000184.

Colburn V. 1999. Trauma in pregnancy. J Perinat Neonatal Nurs 13:21-32.

Connolly AM, Katz VL, Bash KL, et al. 1997. Trauma and pregnancy. Am J Perinatol 14:331-336.

Corona-Rivera JR, Corona-Rivera E, Romero-Velarde E, et al. 2001. Report and review of the fetal brain disruption sequence. Eur J Pediatr 160:664-667.

Crosby WM. 1974. Trauma during pregnancy: maternal and fetal injury. Obstet Gynecol Surv 29:683-699.

El-Kady D, Gilbert WM, Anderson J, et al. 2004. Trauma during pregnancy: an analysis of maternal and fetal outcomes in a large population. Am J Obstet Gynecol 190:1661-1668.

Esposito TJ, Gens DR, Smith LG, et al. 1991. Trauma during pregnancy a review of 79 cases. Arch Surg 126:1073-1078.

Ford JB, Roberts CL, Nassar N, et al. 2010. Recurrence of breech presentation in consecutive pregnancies. Br J Obstet Gynaecol 117:830-836.

Fox MP, Lash TL, Greenland S. 2005. A method to automate probabilistic sensitivity analyses of misclassified binary variables. Int J Epidemiol 34:1370-1376.

Fries MH, Hankins GD, Lackland AFB. 1989. Motor vehicle accident associated with minimal maternal trauma but subsequent fetal demise. Ann Emerg Med 18:301-304.

Gordis L. 2000. Epidemiology. Second ed. Philadelphia: WB Saunders Company.

Greenblatt JF, Dannenberg AL, Johnson CJ. 1997. Incidence of hospitalized injuries among pregnant women in Maryland, 1979-1990. Am J Prev Med 13:374-379.

Grossman NB. 2004. Blunt trauma in pregnancy. Am Fam Physician 70:1303-1310.

Hagmann CF, Schmitt-Mechelke T, Caduff JH, Berger TM. 2004. Fetal intracranial injuries in a preterm infant after maternal motor vehicle accident: a case report. Pediatr Crit Care Med 5:396-398.

Hickok D, Gordon D, Milberg J, Williams M. 1992. The frequency of breech presentation by gestational age at birth: a large populationbased study. Am J Obstet Gynecol 166:851-852.

Honein MA, Paulozzi LJ, Cragan JD, Correa A. 1999. Evaluation of selected characteristics of pregnancy drug registries. Teratology 60:356-364

Hyde LK, Cook LJ, Olson LM, et al. 2003. Effect of motor vehicle crashes on adverse fetal outcomes. Obstet Gynecol 102:279-286.

Ikossi DG, Lazar AA, Morabito D, et al. 2005. Profile of mothers at risk: an analysis of injury and pregnancy loss in 1,195 trauma patients. J Am Coll Surg 200:49-56.

Institute of Medicine: Committee on Improving Birth Outcomes Board on Global Health. 2003. Reducing birth defects: meeting the challenge in the developing world. Washington, DC: The National Academies Press.

Klinich KD, Flannagan CA, Rupp JD, et al. 2008. Fetal outcome in motorvehicle crashes: effects of crash characteristics and maternal restraint. Am J Obstet Gynecol 198:e451-e459.

Klinich KD, Schneider LW, Moore JL, Pearlman MD. 1998. Injuries to pregnant occupants in automotive crashes. 16th International Technical Conference on the Enhanced Safety of Vehicles (ESV). 16th ed. Windsor, Ontario, Canada: NHTSA. pp. 2046-2064.
Knuppel RA, Salvatore DL, Agarwal R, et al. 1994. Documented fetal brain damage resulting from a motor vehicle accident. J Ultrasound Med 13:402-404.

Kuo C, Jamieson DJ, McPheeters ML, et al. 2007. Injury hospitalizations of pregnant women in the United States, 2002. Am J Obstet Gynecol 196:e161-e166.

Kvarnstrand L, Milsom I, Lekander T, et al. 2008. Maternal fatalities, fetal and neonatal deaths related to motor vehicle crashes during pregnancy: a national population-based study. Acta Obstet Gynecol Scand 87:946-952.

Lash TL, Fink AK. 2003. Semi-automated sensitivity analysis to assess systematic errors in observational data. Epidemiology 14:451-458.

Lavin J, Polsky S. 1983. Abdominal trauma during pregnancy. Clin Perinatol 10:423-438.

Leroy-Malherbe V, Bonnier C, Papiernik E, et al. 2006. The association between developmental handicaps and traumatic brain injury during pregnancy: an issue that deserves more systematic evaluation. Brain Inj 20:1355-1365.

Litmanovitz I, Dolfin T, Arnon S, et al. 2000. Fetal intrathoracic injuries following mild maternal motor vehicle accident. J Perinat Med 28:158-160.

Morris J, Rosenbower TJ, Jurkovich G, et al. 1996. Infant survival after cesarean section for trauma. Ann Surg 223:481-488.

Nannini A, Lazar J, Berg C, et al. 2008. Injury: a major cause of pregnancy-associated morbidity in Massachusetts. J Midwifery Womens Health 53:3-10.

Oxford C, Ludmir J. 2009. Trauma in pregnancy. Clin Obstet Gynecol 52:611-629.

Parida SK, Kriss VM, Pulito AR. 1999. Fetal morbidity and mortality following motor vehicle accident: two case reports. J Perinatol 19:144146.

Pearlman MD, Tintinalli J, Lorenz R. 1990. A prospective controlled study of outcome after trauma during pregnancy. Am J Obstet Gynecol 162:1502-1510.

Peckham CH, King RW. 1963. A study of intercurrent conditions observed during pregnancy. Am J Obstet Gynecol 87:609-624.

Petrini J, Damus K, Russell R, Poschman K, Davidoff MJ, Mattison D. 2002. Contribution of birth defects to infant mortality in the United States. Teratology 66(Suppl 1):S3-S6.

Poole GV, Martin JN Jr, Perry KG Jr, et al. 1996. Trauma in pregnancy: the role of interpersonal violence. Am J Obstet Gynecol 74:1873-1877; discussion 1877-1878.

Rayl J, Gibson PJ, Hickok DE. 1996. A population-based case-control study of risk factors for breech presentation. Am J Obstet Gynecol;174(Pt 1):28-32.

Rees S, Harding R. 2004. Brain development during fetal life: influences of the intra-uterine environment. Neurosci Lett 361:111-114.

Rice D, Barone S Jr. 2000. Critical periods of vulnerability for the developing nervous system: evidence from humans and animal models. Environ Health Perspect 108(Suppl 3):511-533.

Richards ID. 1969. Congenital malformations and environmental influences in pregnancy. Br J Prevent Soc Med 23:218-225.

Sauber-Schatz E. 2008. The role of injury in nervous system birth defects and birth trauma during the perinatal period. Pittsburgh: University of Pittsburgh Graduate School of Public Health.

Schiff MA, Holt VL. 2002. The injury severity score in pregnant trauma patients: predicting placental abruption and fetal death. J Trauma 53:946-949.

Schiff MA, Holt VL. 2005. Pregnancy outcomes following hospitalization for motor vehicle crashes in Washington State from 1989 to 2001. Am J Epidemiol 161:503-510.

Schiff MA, Holt VL, Daling JR. 2002. Maternal and infant outcomes after injury during pregnancy in Washington State from 1989 to 1997. J Trauma 53:939-945.

Shah KH, Simons RK, Holbrook T, et al. 1998. Trauma in pregnancy: maternal and fetal outcomes. J Trauma 45:83-86.

Sherer DM, Abramowicz JS, Babkowski R, et al. 1993. Extensive fetal intrathoracic injuries sustained in a motor vehicle accident. Am J Perinatol 10:414-416.

Sival DA. 1993. Studies on fetal motor behaviour in normal and complicated pregnancies. Early Hum Dev 34:13-20.

Stafford PA, Biddinger PW, Zumwalt RE. 1988. Lethal intrauterine fetal trauma. Am J Obstet Gynecol 159:485-489.

Strigini FA, Cioni G, Canapicchi R, et al. 2001. Fetal intracranial hemorrhage: is minor maternal trauma a possible pathogenetic factor? Ultrasound Obstet Gynecol 18:335-342.

Szklo M, Nieto FJ. 2000. Epidemiology beyond the basics. Gaithersburg: Aspen Publishers.

Texas Birth Defects Epidemiology and Surveillance Branch. 2012a. Obtaining data from the Texas Birth Defects Registry: policy and 
request procedures. Available at: http://www.dshs.state.tx.us/birthdefects/Data/access_policy.doc. Accessed Month day, year.

Texas Birth Defects Epidemiology and Surveillance Branch. 2012b. Report of Defects Among 2000-2009 Deliveries. Available at: http:// www.dshs.state.tx.us/birthdefects/data/BD_Data_00-09/Report-ofBirth-Defects-Among-2000-2009-Deliveries/. Accessed Month day, year.

Texas Department of State Health Services. 2012. Tips for Using Texas Birth Defects Registry Data. Available at: http://www.dshs.state.tx.us/birthdefects/tips_bd_data.shtm. Accessed Month day, year.

Tinker SC, Reefhuis J, Dellinger AM, Jamieson DJ. 2010. Epidemiology of maternal injuries during pregnancy in a population-based study, 1997-2005. J Womens Health (Larchmt) 19:2211-2218.

Tinker SC, Reefhuis J, Dellinger AM, Jamieson DJ. 2011. Maternal injuries during the periconceptional period and the risk of birth defects, National Birth Defects Prevention Study, 1997-2005. Paediatr Perinat Epidemiol 25:487-496.
Weintraub AY, Leron E, Mazor M. 2006. The pathophysiology of trauma in pregnancy: a review. J Matern Fetal Neonatal Med 19:601-605.

Weiss B, Landrigan PJ. 2000. The developing brain and the environment: an introduction. Environ Health Perspect 108(Suppl 3):373-374.

Weiss HB. 1999. Pregnancy-associated injury hospitalizations in Pennsylvania, 1995. Ann Emerg Med 34:626-636.

Weiss HB. 2006. The hidden epidemic of maternal, fetal and neonatal mortality and injury due to motor vehicle crashes during pregnancy: a case of societal neglect? Transp Res Rec 1956:133-140.

Weiss HB, Sauber-Schatz EK, Cook LJ. 2008. The epidemiology of pregnancy-associated emergency department injury visits and their impact on reproductive outcomes. Accid Anal Prev 40:1088-1095.

Weiss HB, Songer TJ, Fabio A. 2001. Fetal deaths related to maternal injury. JAMA 286:1863-1868.

Wolf ME, Alexander BH, Rivara FP, et al. 1993. A retrospective cohort study of seatbelt use and pregnancy outcome after a motor vehicle crash. J Trauma 34:116-119. 